\title{
Street Lighting System For Smart Cities Using Micro- Controllers
}

\author{
Aaquib Parkar, Prashant Kumar Soori \\ Department of Electrical and Electronics Engineering, Heriot Watt University Dubai Campus, \\ United Arab Emirates
}

\author{
Article Info \\ Article history: \\ Received Feb 15, 2018 \\ Revised Apr 12, 2018 \\ Accepted Apr 28, 2018

\section{Keywords:} \\ Arduino \\ IALux \\ Energy \\ High Pressure Sodium (HPS) \\ lamp \\ Light Emitting Diodes (LED) \\ Raspberry Pi \\ Sensors
}

\begin{abstract}
The main goal is to simulate different configurations of street lighting system using DIALux and optimize the energy consumption. Data of the existing road in the United Arab Emirates is considered for simulation. Simulation results are validated by building a hardware model. This is accomplished by using LED modules instead of traditional HPS bulbs which is connected to an Arduino to control different sensors. Photo resistors are used to automatically switch the lights ON or OFF depending on the light intensity. Ultrasonic sensors are used to detect motion of cars and pedestrians in order to switch $50 \%$ of the lights off if no motion is detected. The recorded data is monitored by a Raspberry Pi which acting as a monitoring device. Practical measurements were conducted at different points on the road selected and are compared with the simulation results.
\end{abstract}

Copyright (c) 2018 Institute of Advanced Engineering and Science. All rights reserved.

\section{Corresponding Author:}

Aaquib Parkar,

Department of Electrical and Electronics Engineering,

Heriot Watt University Dubai Campus, United Arab Emirates.

Email: ap327@hw.ac.uk

\section{INTRODUCTION}

A street light is a raised source of light usually found at the edge of a road or a walkway. They can be switched on manually or using sensors like light sensitive photocells or with the aid of a solar dial in the case of the older lighting system. Most street lights are connected underground instead of wiring one utility post to another.

Modern street lights usually comprise of high-intensity discharge (HID) lamps like High-pressure sodium (HPS) lamps. HPS lamps provide a large amount of illumination for a fairly low consumption of electricity. Compared to HPS light which is usually yellow/orange, white light sources are known to double driver's vision as well as reduce the braking reaction time by a minimum of $25 \%$. Newer street lights use light emitting diodes (LED) which provide high levels of lumens for a very low consumption of electricity [1].

Street lights can be made intelligent by using different sensors which can trigger them when they detect something moving [2]. Software can be used to make them communicate with each other and can be monitored wirelessly.

To improve the efficiency of street lighting system design, different types of configurations are researched and highlighted in this paper [3]. A prototype system demonstrating smart street light system has been built which uses two 190W LED light panels. The LED lights have been connected to different sensors which enable them to switch on and off based on the light intensity around them and dims the panels if no movement is detected around the light panels. 
Smart street light is a technique used in street lights that adapt to movement of different objects like pedestrians and cars.These streetlights can be controlled and connected using IoT also [4]. The streetlights dim when there is no activity detected and brightens up when there is movement [5]. Smart street lights can even switch themselves on when the light intensity around it decreases.

In 2013 a research team from Finland published a paper stating how energy efficiency can be improved by using modern LED technology and adding integrated sensors [6]. Adaptive lighting which is set to respond to the presence of pedestrians can save an average of $40 \%$ power which was achieved by dimming down the power to $50 \%$ after five minutes delay from the last detection.

In 2011 a team of researchers from Serbia published a paper on the amount of energy being saved by switching to LED luminaires [7]. For collector roads (i.e. roads with low to medium traffic density) LED require 1\% (staggered layout) and 10\% (single sided layout) less power and for local roads, on average 6\% and $24 \%$ less power is used when compared to HPS street lights.

In 2013 a research team from Spain suggested an easy approach to deploy street light control system with wireless technology [8]. The paper involved designing an intelligent streetlight management system based on LED which could facilitate its deployment in existing facilities. Their proposed approach will minimize the cost of investment of traditional wired system.

In 2016 a team of students in India published their findings on Smart Streetlight system based on Image Processing [9]. Their article presents a concept to boost the energy efficiency of a city. Their system uses a timer to switch on the light in the evening and switch it off in the morning. The system uses sensors to detect vehicle and human presence on highways to switch on a chunk of lights ahead of it and switch off the trailing lights. This was achieved by processing the image of approaching objects and then sending commands to street light blocks.

In 2017 a research team published a paper on the advantages of using LED street lights and integrating IoT into their proposed model [10].

The first patent for the smart street light was filed in the late 1990s [11]. The first large-scale implementation of the smart street light system was done on 7th April 2006 in Oslo Norway and was expected to reduce usage by $50 \%$ while improving road safety and minimizing maintenance costs [12]. The Oslo project caught the attention of other European cities to reduce energy usage in outdoor lighting systems in the European Union (EU).

In this project, various simulations were performed using DIALux to check the performance of different street light luminaires and compare their energy consumptions [13]. The simulation also helped in determining the ideal distance between two street light poles and the ideal angle for the luminaire on the pole along with the ideal distance for the pole to be placed away from the road.

The prototype constructed uses two 190W LED light panels. The LED panels are controlled using different sensors such as an ultrasonic for motion detection and photoresistors to check the intensity of light in the surroundings. The sensors are controlled by an Arduino Mega microcontroller which is connected to a Raspberry Pi 3 that acts as a monitoring device which can update the code of the Arduino using a virtual network connection (VNC). Figure 1 shows the schematics of hardware implementation of the prototype model.

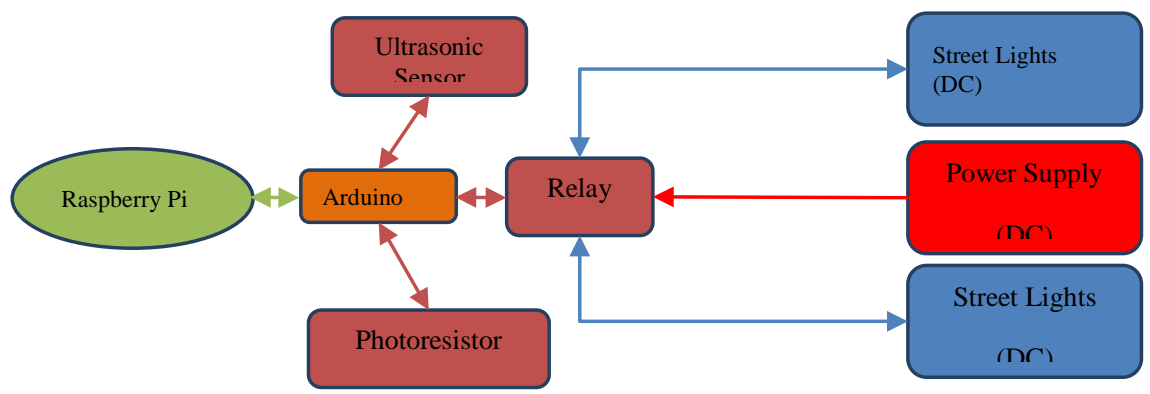

Figure 1. Block Diagram of Hardware Implementation

\section{RESEARCH METHOD}

\subsection{System Details}

1) Arduino MEGA

The Arduino microcontroller uses an ATmega 2560 processor. This system provides sets of 54 digital and 16 analog input/output pins that may be interfaced to various circuits and expansion boards (shields). The board features a universal serial bus (USB) for loading programs. The board is programmed 
using dialects from programming languages like $\mathrm{C}$ and $\mathrm{C}++$. In this project, the Arduino is used to send and receive data from various sensors.

2) Raspberry Pi 3

The Raspberry Pi 3 is a small sized single-board computer using a 64-bit quad-core ARM CortexA53 processor. The Raspberry Pi 3 is compatible with different operating systems (OS) like Windows Internet of Things(IoT), Linux, Raspbian based on the user requirements. In this project, the raspberry pi is used to monitor the data from the Arduino wirelessly.

3) Ultrasonic Sensor

Ultrasonic sensors are used to detect motion and measure distance from the sensor to an object it is facing. Ultrasonic sensors are used in many automated industries and process plants. The sensors have digital on and off outputs for detecting the movement of objects and an analog output that is proportional to the distance. Ultrasonic sensors can also be used to detect liquid level measurement and objects with target translucence, and they can even operate in environments with a high glare. Ultrasonic sensors are being tested for ultrasonic people detection in cars and autonomous features in an unmanned aerial vehicles (UAV).

The ultrasonic sensor used in this project is HC-SR04. This economic sensor has a range from $2 \mathrm{~cm}$ to $4 \mathrm{~m}$ of noncontact measurement with an accuracy of $3 \mathrm{~mm}$. Each module has an ultrasonic transmitter, receiver, and a control circuit.

4) Light Intensity Sensor

A photoresistor is a light controlled variable resistor. The resistance of the photoresistor is proportional to the intensity of light. It is made up of a high resistance semiconductor and can have a resistance of several megaohms (M $\Omega$ ) when kept in the light. Photoresistors can be used in various items like camera light meters, clocks, and nightlights. The sensor used for this project is a 5528 model photoresistor.

5) Relay Module Board

A relay module board is used to connect an external power supply to different components used by the Arduino. For this project, a two-channel relay is used which can handle AC up to 250V,10A and DC up to $30,10 \mathrm{~A}$.

\subsection{Hardware Implementation}

For this project, Arduino Mega is used as the main control device. There is an ultrasonic sensor and two photoresistors connected to the digital pins on the Arduino which transmit their data every 10ms. Based on the values received from the sensors by the Arduino it can send the appropriate commands to the relay whether to switch the street lights on or off. This whole process can be monitored as the data is transmitted by the raspberry pi wirelessly. Changes to the Arduino program can also be done wirelessly.

\subsection{Experimental Data Collected}

1) Main Distributor Road

Data collected from a main Distributor Road located in United Arab Emirates is:

Road Length :- 2550m approximately

No of Street Light Poles :- 51

Distance Of Separation :- 50m

Length of Pole :- $16 \mathrm{~m}$

No. Of Bulbs on each Pole :- 2

Power Of Bulb :- 400W

Energy Consumption of one pole/Day(Based on 11 Hours per Day) :- 8.8kWh

Energy Consumption of entire street/Day(Based on 11 Hours per Day) :- 448.8kWh

Manufacturer Of Bulb :- Nikkon

2) Link Road

Bulb Type :- HPS

Road Length :- 950m approximately

No of Street Light Poles :- 31

Dist. Of Separation :- 30m

Length of Pole :- $10 \mathrm{~m}$

No. Of Bulbs on each Pole :- 1

Power Of Bulb :- 250W

Energy Consumption of one pole/Day(Based on 11 Hours/Day) :- 2.75kWh

Energy Consumption of entire street/Day(Based on 11 Hours/Day) :- 85.25kWh

Manufacturer Of Bulb :- Nikkon

Bulb Type :- HPS 
3) LUX Readings

LUX readings were taken on different portions of the road as given in Figure 2 and Figure 3.

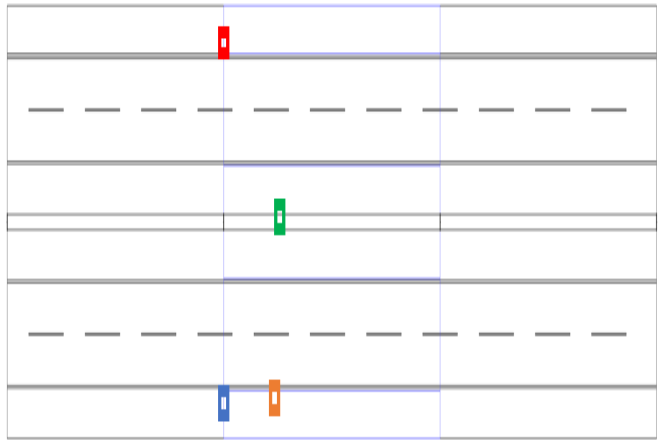

Figure 2. Readings taken on different portions

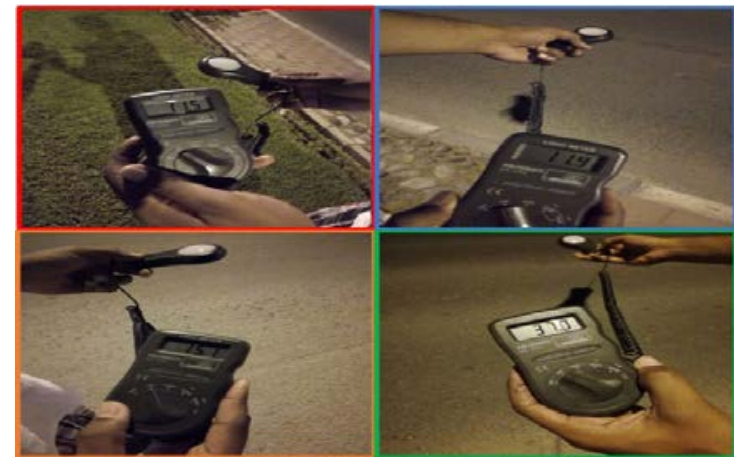

Figure 3. LUX Readings Taken for HPS

\section{RESULTS AND ANALYSIS}

\subsection{Main Distributor Road}

Simulation is carried out for the data collected for the Main Distributor Road and simulation results for HPS lamp (400W each) are presented in Fig. 4-8 below.

1) HPS Lamp

Parameters Used for Main Distributor Road

Comparing the readings taken in Figure 3 using a LUX meter with the simulated readings in Figure 7, it can be seen that the experimental values are very close to the simulation results.

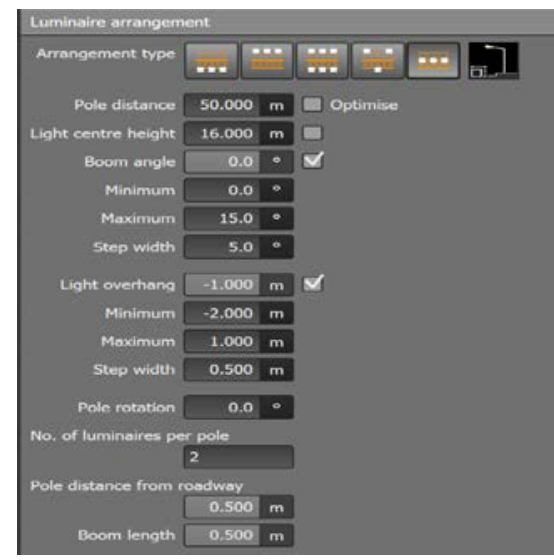

Figure 4. Simulation Parameters Used for HPS Lamp

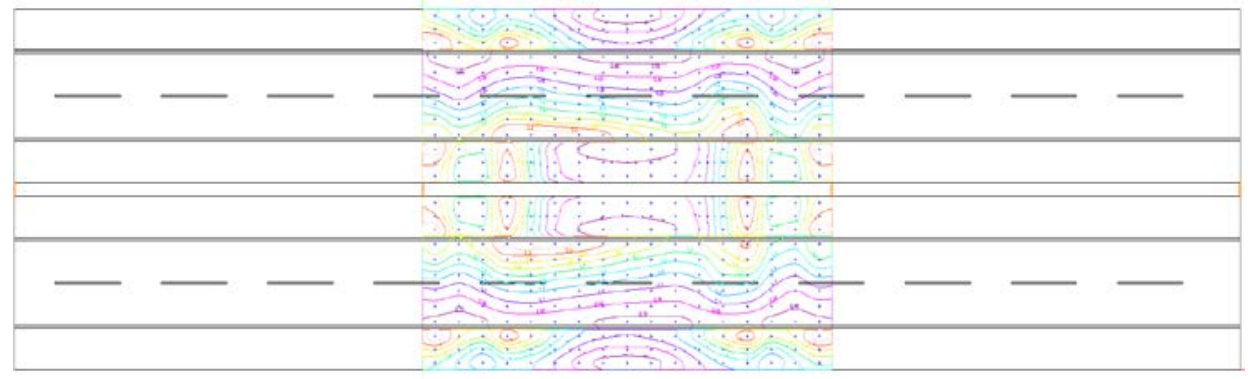

Figure 5. 2-D layout of the Road for HPS Lamp 


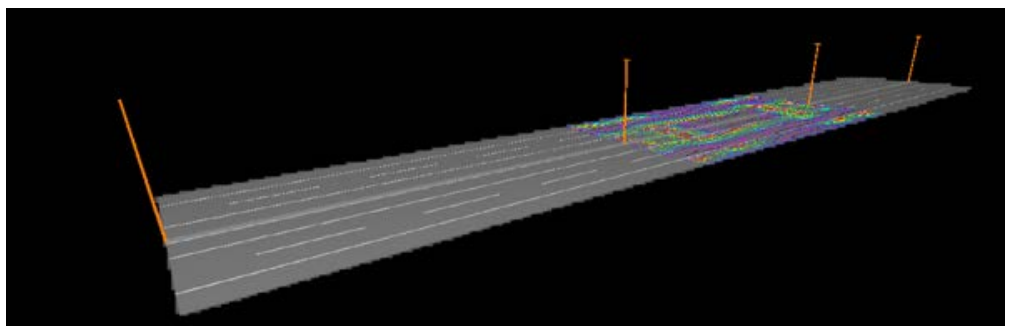

Figure 6. 3-D layout of the Road for HPS Lamp

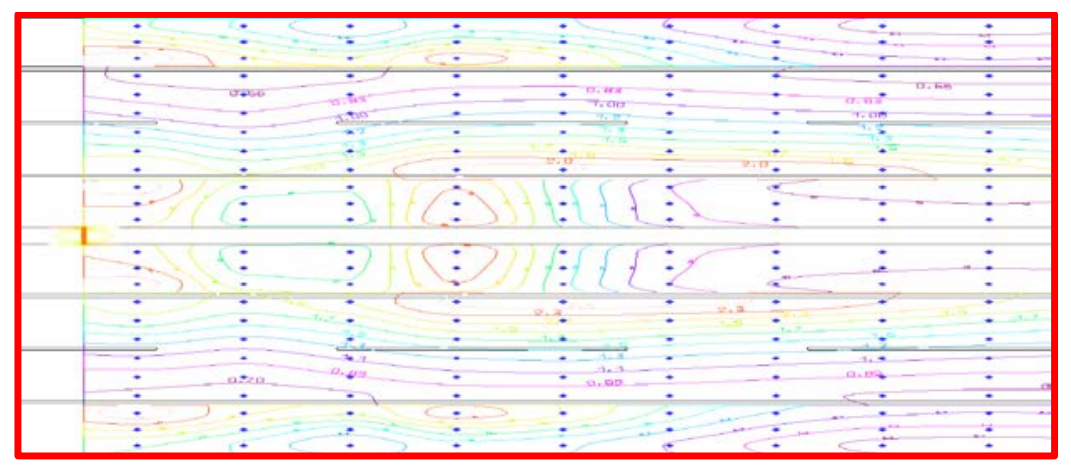

Figure 7. Detailed View of 2-D layout of the road with simulated LUX Readings for HPS Lamp

Table 1. Comparison Between Simulated and Experimental Values

\begin{tabular}{ccccc}
\hline S. No. & 1 & 2 & 3 & 4 \\
\hline Experimental & 11.5 & 11.9 & 15.1 & 37.0 \\
Reading(LUX) & & & & 39.0 \\
Simulated & 11.0 & 13.0 & 14.0 & 3.0 \\
Reading(LUX) & 0.5 & 1.1 & 0.9 & 2.0 \\
Difference & &
\end{tabular}

Figure 8 shows the complete evaluation of the simulation result with HPS Lamp. It can be seen that the results are matching with the International standards.

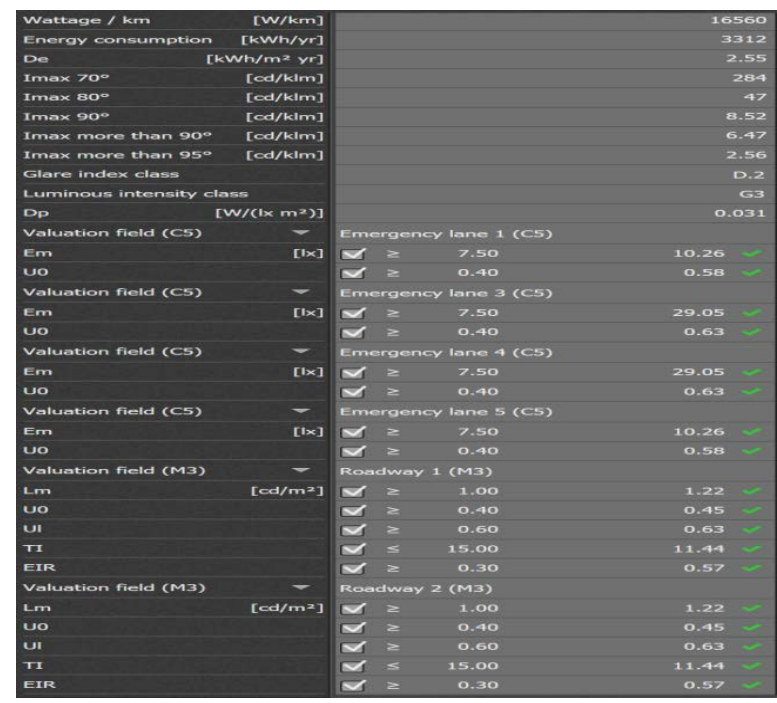

Figure 8. Simulation Results Obtained for HPS Lamp 


\section{2) LED Lights}

Simulations are carried out by changing the luminaire to LED Panels (190W each) and are presented in Figure 9-12.

The distance between poles was reduced from 50m in the case of HPS to 35m for LED lights while the height of the pole was reduced from $16 \mathrm{~m}$ for HPS to $14 \mathrm{~m}$ for LED lights. This was done to meet the requirements for the international standards for street lighting system design.

Figure 12 shows the complete evaluation of the simulation result with LED Lamps. It can be seen that the results are matching with the International standards.

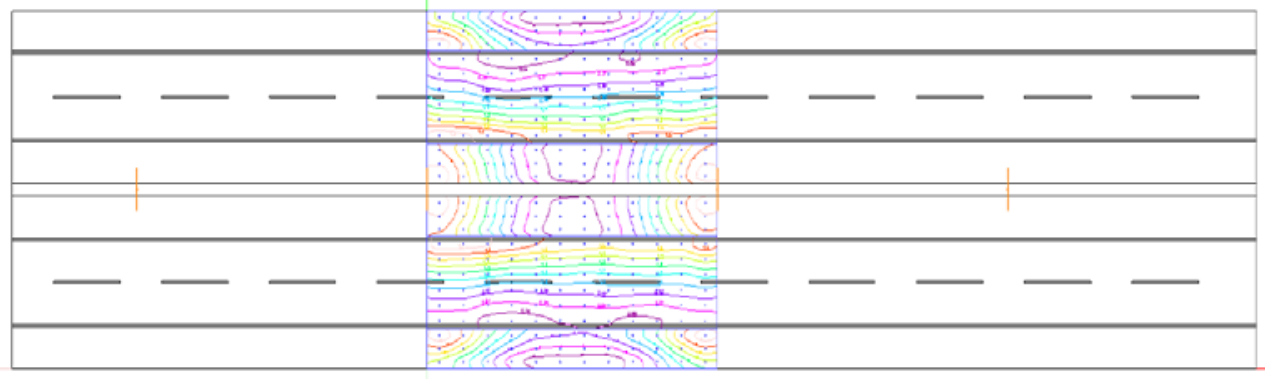

Figure 9. 2-D Layout of the road for LED Panels

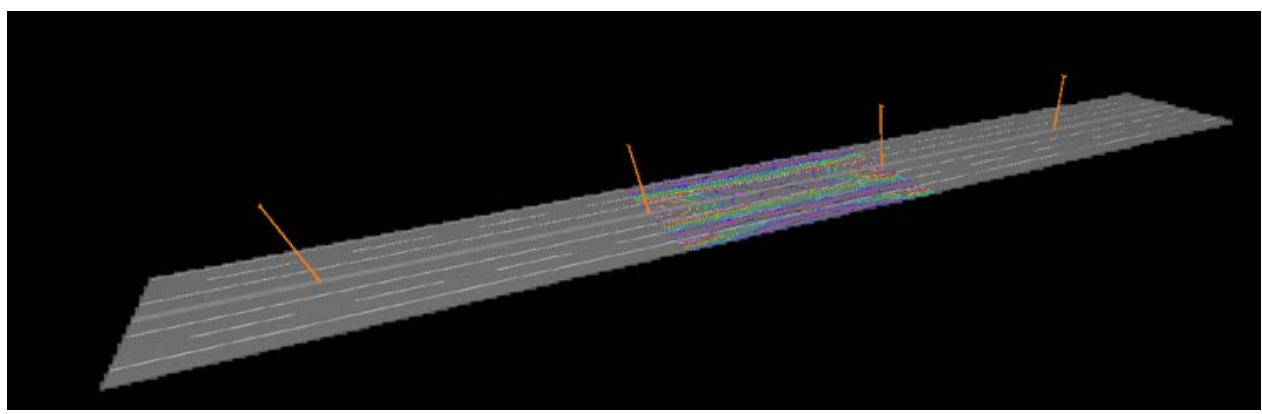

Figure 10. 3-D Layout of the Road for LED Panels

Parameters Used for Main Distributor Road

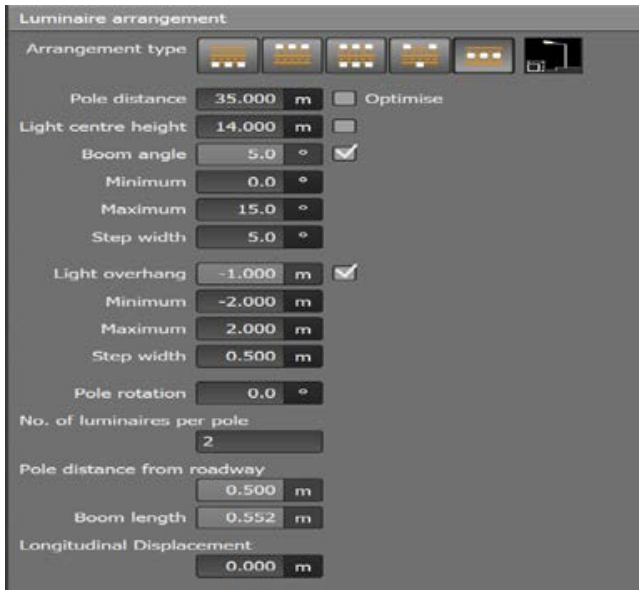

Figure 11. Parameters Used for the Simulation of LED Panels 


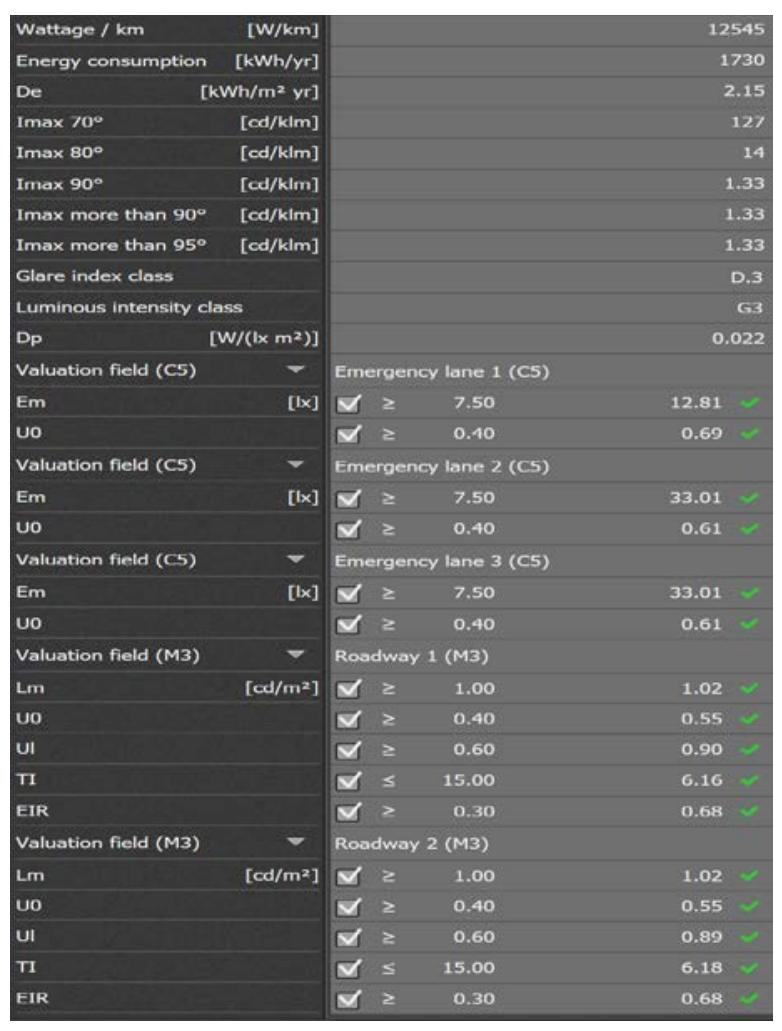

Figure 12. Simulation Results Obtained for LED Panels

\subsection{Link Road}

Simulation is carried out for the data collected for the Link Road and simulation results for HPS lamp (250W each) are presented in Fig. 13-14 below.

1) HPS Lamp

Parameters Used for Main Distributor Road

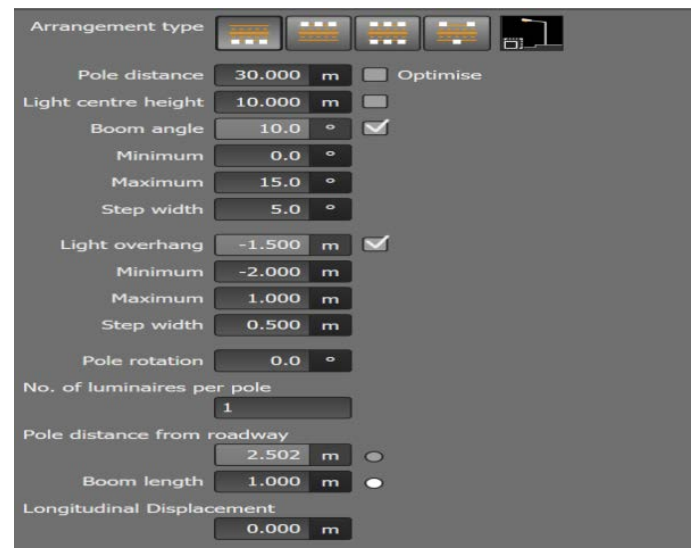

Figure 13. Simulation Parameters Used for HPS Lamp

Figure 14 shows the complete evaluation of the simulation result with HPS Lamp. It can be seen that the results are matching with the International standards. 


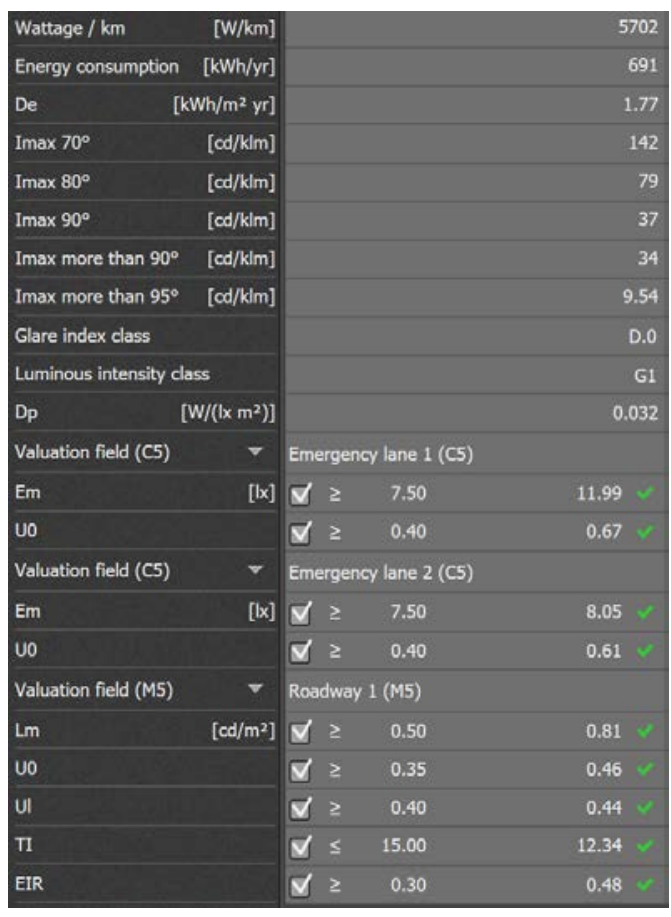

Figure 14. Simulation Results Obtained for HPS Lamp

2) LED Lights

Simulations are carried out by changing the luminaire to LED Panels (90W each) and are presented in Figure 15-16.

Parameters Used for Main Distributor Road

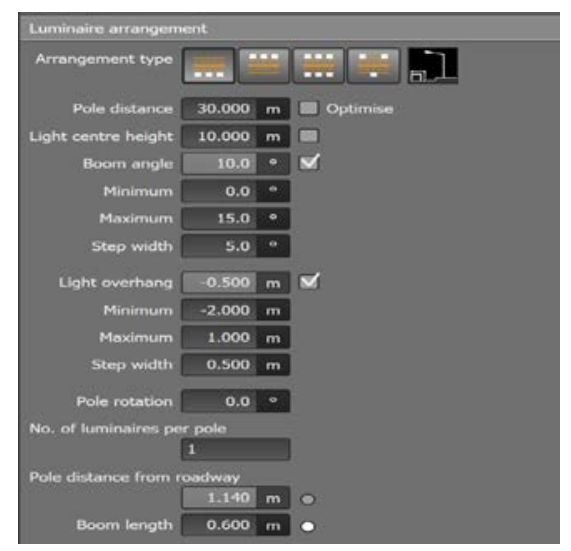

Figure 15. Parameters Used for the Simulation of LED Panels

Figure 16 shows the complete evaluation of the simulation result with LED Lamps. It can be seen that the results are matching with the International standards. 


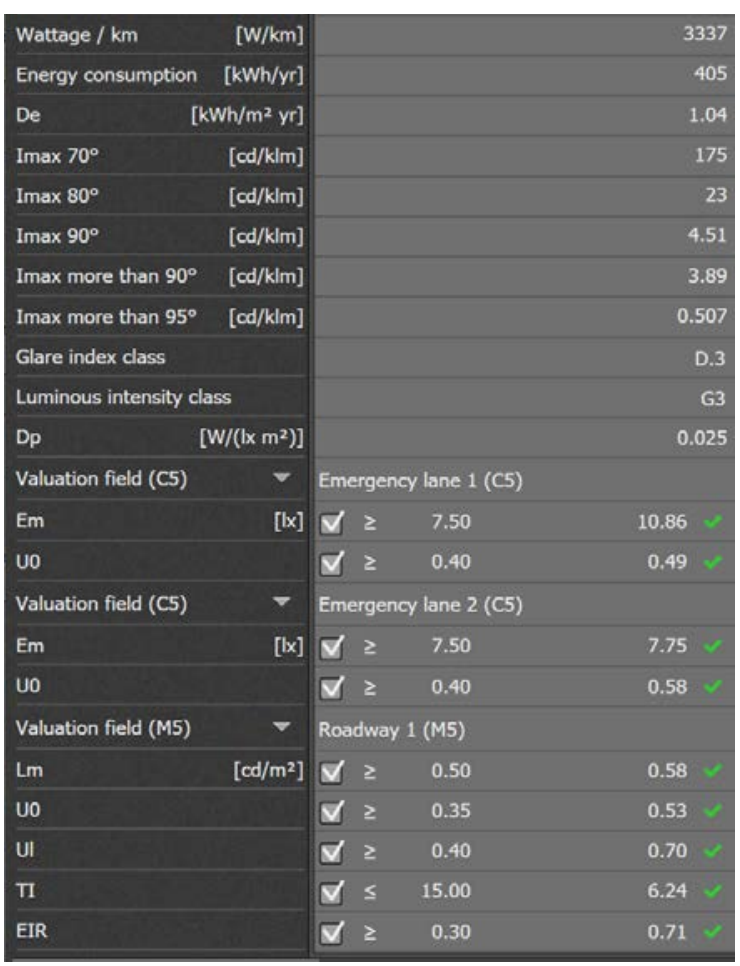

Figure 16. Simulation Results Obtained for LED Panels

\section{CONCLUSION}

When comparing the simulation results for Main Distributor Road using traditional HPS Lamps (Figure 8) and LED panels (Figure 12), we can observe that energy consumption has reduced by a large margin. With HPS lamps, total energy consumption is $3312 \mathrm{kWh} /$ year while with LED panels, total energy consumption is $1730 \mathrm{kWh} /$ year.

Hence $1582 \mathrm{kWh}$ of energy can be saved every year. Thus by replacing the lamps from HPS to LED there will be $47.77 \%$ reduction in energy consumption and it is expected to save more energy due to the intelligence system adopted.

However, it is observed that the light intensity is less for LED panels (1.02) when compared to HPS lamps (1.22). The light is more uniform for LED (0.89) when compared to HPS (0.63) while the glare is lesser for LED (6.18) in comparison to HPS (11.44).

When comparing the simulation results for Link Road using traditional HPS bulbs (Figure 14) and LED panels (Figure 18) we can observe that energy consumption has reduced by a large margin. HPS bulbs need $691 \mathrm{kWh} /$ year while LED panels need $405 \mathrm{kWh} /$ year.

Hence $691 \mathrm{kWh}$ of energy can be saved every year. Thus by replacing the lamps from HPS to LED there will be $41.4 \%$ reduction in energy consumption and it is expected to save more energy due to the intelligence system adopted.

The light intensity is less for LED panels(0.58) when compared to HPS bulbs (0.81). The light is more uniform for LED (0.70) when compared to HPS(0.44) while the glare is lesser for LED (6.24) in comparison to HPS (12.34).

Street Lights are important for our day to day purpose. Street Lighting System For Smart Cities Using Micro-Controllers presents ways to improve their efficiency by using up to date technology and reduce their energy consumption. Using the proposed system, over $47 \%$ energy can be saved.

\section{REFERENCES}

[1] Gunabalan, R. (2016). Overview of Passive Light Emitting Diode Driver Circuits for Street Lighting. [online] Available at: http://journal.portalgaruda.org/ [Accessed 15 Dec. 2016].

[2] Zhu, J. and Raison, C. (2014). Cost Effective Automated Street Lighting Control. [online] Iaescore.com. Available at: http://iaescore.com/journals/index.php/IJECE/article/view /5554/4868 [Accessed 3 Mar. 2017].

[3] Ieeexplore.ieee.org. (2010). Design of new intelligent street light control system - IEEE

[4] Ieeexplore.ieee.org. (2018). IoT-based dynamic street light control for smart cities use cases - IEEE Conference Publication. [online] Available at: http://ieeexplore.ieee.org/document/7746112/ [Accessed 11 Dec. 2016]. 
[5] Ieeexplore.ieee.org. (2017). Research of Intelligent Street Light System Based on ZigBee - IEEE Conference Publication. [online] Available at: http://ieeexplore.ieee.org/document/7823535/ [Accessed 4 Jan. 2017].

[6] Conference Publication. [online] Available at: http://ieeexplore.ieee.org/document/5524348/references [Accessed 10 Mar. 2017].

[7] Juntunen E, Tetri E, Tapaninen O, Yrjänä S, Kondratyev V, Sitomaniemi A, Siirtola H, Sarjanoja EM, Aikio J, Heikkinen V. A smart LED luminaire for energy savings in pedestrian road lighting. Lighting Research \& Technology. 2013; 47(1): 103-115.

[8] Kostic AM, Kremic MM, Djokic LS, Kostic MB. Light-emitting diodes in street and roadway lighting - a case study involving mesopic effects. Lighting Research \& Technology. 2012; 45(2): 217-229.

[9] Elejoste P, Angulo I, Perallos A, Chertudi A, Zuazola IJG, Moreno A, Azpilicueta L, Astrain JJ, Falcone F, Villadangos J. An easy to deploy street light control system based on wireless communication and LED technology. Sensors. 2013; 13(5): 6492-6523.

[10] Veena PC, Tharakan P, Haridas H, Ramya K, Joju R, Jyothis TS. Smart street light system based on image processing. 2016 International Conference on Circuit, Power and Computing Technology (ICCPCT). Nagercoil. 2016: $1-5$.

[11] Satrya GB, Reda HT, Woo KJ, Daely PT, Shin SY, Chae S. IoT and public weather data based monitoring \& control software development for variable color temperature LED street lights. International Journal on Advanced Science, Engineering and Information Technology. 2017; 7(2): 366-372.

[12] Levy J. Intelligent outdoor lighting control system. 6204615(Patent). 2001.

[13] W Budiharto, A Santoso, D Purwanto, A Jazidie. Multiple moving obstacles avoidance of service robot using stereo vision. TELKOMNIKA (Telecommunication, Computing, Electronics and Control). 2011; 9(3): 433-444.

[14] GmbH D. Better architecture through light and automation - DIAL [Internet]. Available from: https://www.dial.de/en/home/ 